\title{
A review on cloud based knowledge management in higher education institutions
}

\author{
Ahmad Shukri Mohd Noor' ${ }^{1}$, Muhammad Younas ${ }^{2}$, Muhammad Arshad \\ ${ }^{1,2}$ Universiti Malaysia Terengganu, Kuala Terenggnue, Malaysia \\ ${ }^{3}$ Jazan University, Jazan, Saudi Arabia
}

\begin{tabular}{l} 
Article Info \\
\hline Article history: \\
Received Apr 1, 2019 \\
Revised Jun 20, 2019 \\
Accepted Jun 27, 2019 \\
\hline
\end{tabular}

Keywords:

Cloud computing

Higher education institutions

Highlights and challenges

Knowledge management

\begin{abstract}
Knowledge Management (KM) is widely discussed by researcher and attracts many enterprisers to extract, dispense and use information in a systematic way under Knowledge Management System (KMS). New technology adoption within the knowledge management system is one of the core issue, identified by researcher and underlined as future research agenda. Cloud computing becomes the most adoptable choice for enterprisers to reduce infrastructure and maintenance cost by shifting business on the cloud. Higher Education Institutions (HEIs) are more enthusiastic about knowledge management due to its primary goal of knowledge creation and sharing. Cloud based knowledge management attract higher education institutions by changing the educational method and objectives due to innovative trends in technology. This exploratory research based on literature review for cloudbased knowledge management, targeting higher education institutions. This study highlights the benefits and challenges associated with cloud-based knowledge management system and its impact on knowledge.
\end{abstract}

Copyright $(0) 2019$ Institute of Advanced Engineering and Science. All rights reserved.

\section{Corresponding Author:}

Ahmad Shukri Mohd Noor,

Associate Professor,

Universiti Malaysia Terengganu,

Kuala Terengganu, Malaysia.

Email: ashukri@umt.edu.my

\section{INTRODUCTION}

The rapid development in the field of technology causes the end result of mass data creation. This data is inadequate for organization without extracting the required and important information. The process of transformation from data to information is called knowledge. In other words "Ready form of Information extracted from data is called Knowledge". Existence of Knowledge is everywhere with extensive range of categories and big quantities [1]. Knowledge Management process include creating new knowledge, retrieving important knowledge from external sources, use knowledge for decision making purpose, embedding knowledge in processes, share knowledge between inside and outside of the organization [2].

Technological dependency is common today's age and its benefits overwhelm its disadvantages. Educational institutions are adopting latest technologies to meet the contemporary education requirements from admission to result, hiring to firing, staff assessment, teaching load allocation and distance learning. Knowledge creation and sharing was considered as the main objective for higher education but with the passage of time and innovative trends in technology, the educational method and objective also changed. Universities are adopting economic development, and enterprise as revolution in their mission [3]. Higher education, especially the universities seems to be an attractive type of businesses suitable for initiating KM practices [4]. KM can promote the professional development, scientific research proficiency and teaching level of university staff [5]. KM in higher education institutions can boost the institutional success in term of education and social values as well as lead to good decision based on available knowledge. 
Cloud computing is latest and famous technology nowadays and many enterprisers are making a shift towards its advantages. Needless to mention the associated benefits such as high computational power, reduction in infrastructure and maintenance costs coupled with on-demand storage capacity. Cloud computing can be defined as a setup where storage and all data processing happen beyond the user's devices and the date traverse through these databases [6].

The main aim of this paper is to assess the benefits and challenges of cloud-based knowledge management by targeting higher education institutions. Rest of paper will cover the following areas. Section II and III describes knowledge management and cloud computing in detail, section IV discusses its related works, section V Knowledge Management Systems using Cloud Computing, section VI analyses and discussion and finally conclusion in section VII.

\section{KNOWLEDGE MANAGEMENT}

Knowledge is useful information in ready form and how and when to use this information is called Knowledge Management. In other words trick to extract required information from available raw data is called Knowledge Management. Knowledge can be categories into two main types that are explicit knowledge and implicit knowledge [7]. According to some websites Knowledge can be divided into three types that are explicit, implicit and tacit knowledge [8]. Knowledge that is easy to record and share is called explicit knowledge. Implicit knowledge is transferable skills with job switching. Knowledge that is gained from personal experience is called tacit Knowledge. Transfer tacit knowledge into explicit knowledge is one of the main KM task [9].

$\mathrm{KM}$ is widely accepted term as the world is continuously moving towards knowledge-based economy. KM belongs to same class of management like time management and self-management with the aim of creating and sharing the knowledge in the best interest of organizational practices. Many authors define knowledge management in their own way as no general accepted definition exists and most of them are similar. According to [10] Knowledge is top level information ready to use for decisions and actions and it is combined with experience, context, interpretation and reflection. According to [11]. The term knowledge management refers to identifying, method of achieving, saving, managing and sharing. According to [12], $\mathrm{KM}$ is a process where organizations have formulated ways in the attempt to recognize and archive knowledge assets within the organization that are derived from the various employees. Nowadays KM is considering as integrated part of all domains and enterprises [13]. Figure 1 shows Tree diagram for knowledge management.

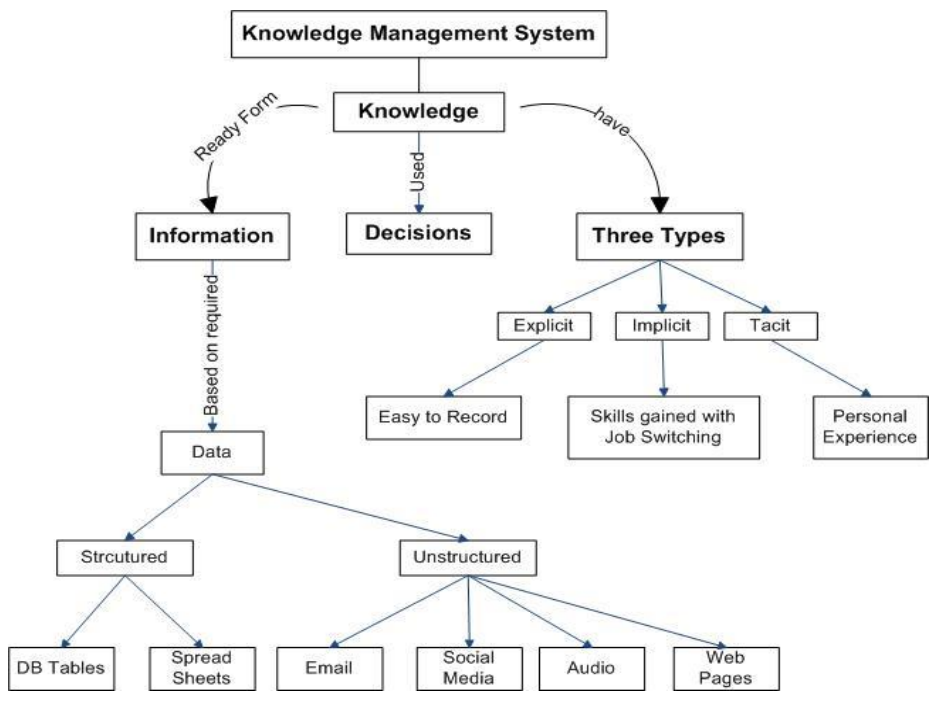

Figure 1. Knowledge management system tree diagram

\section{CLOUD COMPUTING}

Cloud Computing refers an online storage of Organization's data as well as infrastructure. Cloud computing is general term referred as the delivery of on-demand computing resources- everything from application to data centers- over the internet on a pay-for-use basic. Cloud computing is a setup where 
storage and all data processing happen beyond the user's devices go through these databases [6]. A distributed computing application delivered as a service over the Internet and provides dynamically and scalable computing resources including storage, computation power [14, 15].

Cloud computing have three main models that are also known as services Models. These models are:

1. Software as a Service (SaaS) also known as Software on demand Service.

2. Platform as a service (PaaS).

3. Infrastructure as a Service (IaaS).

Cloud computing groups into four main types also known as deployment model [16]. These types are:

1. Private cloud

2. Public cloud

3. Community Cloud

4. Hybrid Cloud

Many websites and authors also define some more subtype based on multi character. According to Wikipedia [17] other cloud computing subtypes are Distributed Cloud, Multi Cloud, Big Data Cloud and High Performance Computing(HPC) Cloud.

Cloud computing model composed of following five key characteristics.

1. On demand self service

2. Broad network access

3. Resource pooling and multi tenancy

4. Rapid elasticity and scalability

5. Measured service

Cloud computing tree diagram shown in Figure 2.

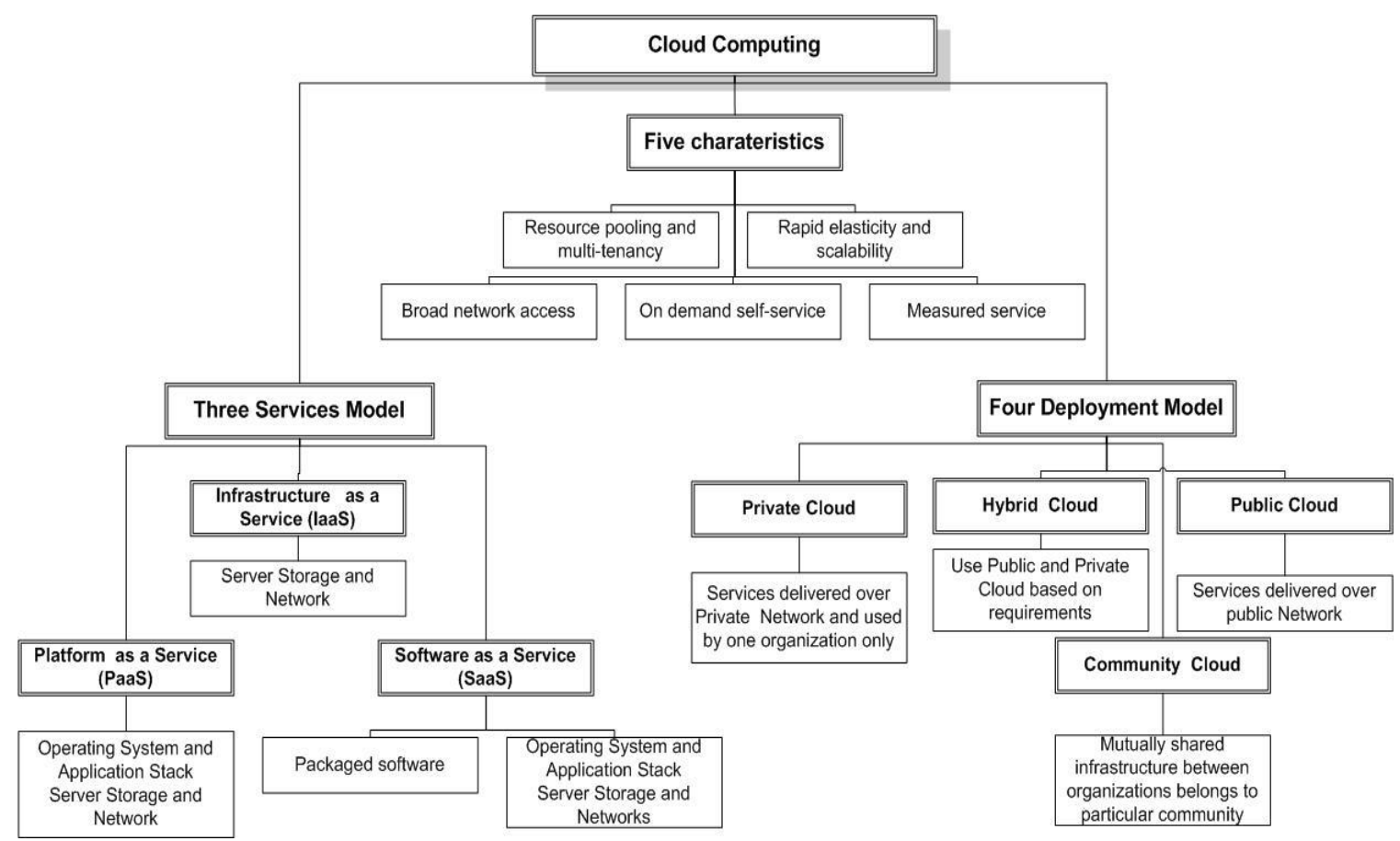

Figure 2. Cloud computing tree diagram

\section{RELATED WORK}

Many researchers have done a lot of work in the field of knowledge management and its integration with cloud computing including benefits and issues. For the tenacity of this paper we explore previous research studies in the field of knowledge management and Cloud Computing, try to find existing work recommended both in the literature and on the web. 
Keeping in mind the new technology acceptance issues [18] discuss the significances of cloud computing implementation in education sector to achieve knowledge management. Research model was analyzed and validate using structural equation technique with the help of survey data collected from students. Knowledge sharing and synchronization practice was done using drop box accounts to fulfil the cloud computing environment. Technology Acceptance Model (TAM) was used to verify result and proposed extended model is supposed to be more defensible in term of knowledge creation, sharing, storage and application.

Knowledge management implementation using cloud computing describe by [19] with case study in Computer Science High School. Obstacles in Knowledge management system (KMS) implementation such as expensive IT infrastructure as well as maintenance cost was discussed in detail and recommend cloud computing as alternate to overcome such barriers. Knowledge Management System Agile Implementation Methodology (KMSAIM) used for cloud based KMS implementation with PaaS platform from google (App Engine) and Microsoft (Windows Azure) in case study. Author also highlight that the non-technical barrier such as governmental procedures may also a cause for slow KMS implementation processing.

In [20] author focus on gathering and sharing the teaching experience in term of knowledge management within university e-learning environment using cloud computing and Web 2.0. Cloud based knowledge management architecture was proposed to manage the best teaching experience by facilitating user to retrieve and share knowledge. The core users of cloud based knowledge management system with in university are learners, instructors and developers. The main modules for proposed architecture include knowledge acquisition, refinement and retrieval. Author use a case study to testify the result by using knowledge creation template as an example in many advantages also claimed by author in favor of proposed KMS.

A detail systematic review done by [21] focuses on current issues in knowledge management systems(KMS). Author identified several problems but highlighted three important issues after narrowing the result set. These issues in knowledge management system are new technology adoption in KMS, big data in KMS and capabilities development and features of KMS.

An interview based empirical research carried out by [22] and result shows that cloud computing can contribute in knowledge management by improving decision making processes, response time reduction, profitability, problems of growth reduction and productivity. Cloud computing implementation in different areas of knowledge management discussed in detail with benefits that include accessing latest technology, supporting tool for knowledge transfer and sharing, reduce processing time, reliable IT resource availability with performance. Associated risk include no control on IT environment, IT staff reduction, Cloud services dependency, loss or unauthorized use of high profile data.

H. Ramayani, et al. [23] describes KM through cloud computing and use higher education institution as case study. Literature review methodology used with organizational KM portal and PaaS as cloud participant. The result shows that online KM portal can increase the overall university performance by boosting work efficiency and knowledge of employee. Author believes that the staff cooperation in term of information sharing towards KM is main pillar of KM success.

\section{KNOWLEDGE MANAGEMENT SYSTEMS USING CLOUD COMPUTING}

The process of gaining, creating and dispensing knowledge belongs to knowledge management and technological implementing of knowledge management in organization is called Knowledge Management System (KMS) [24, 25]. Presently, knowledge management has gained high recognition by both Higher Educational and its subsidiaries and earned a space not only for knowledge delivery but also become a standard for activities related to curricula design and knowledge sharing processes. Hence, knowledge management implementation will significantly elevate knowledge structure, academic processes, and easy decision making for management in higher education. Further, knowledge management implementation can dramatically contribute to increment of adoption ability of learning tools via new IT technologies assist academic processes [26]. The incessant innovative advancement in today's IT industry in all domains creates broad spectrum of opportunities for knowledge management to further expand. In other words the latest trends in IT obligate KM to align with this dynamic environment. Cloud computing provide practical management tools and offers internet space to ensure the knowledge attainable and manageable in virtual form [26]. Cloud computing's technology can be leveraged to manage a wide range of knowledge and services in order to effectively meet the needs of the organization with efficacy.

Higher Education Institutions are suffering new challenges including dynamic educational reform, low budget, mass data creation, growing need of IT infrastructure, innovative trends in technology and digital educational methodology. These issues pay attention for concern authorities to find alternate and state of the art solution to overcome these problems. 
Cloud based knowledge management is an attractive solution for above issues and meet all contemporary requirements for any organization including higher education institution. Knowledge management can be phenomenally benefited with the cloud computing integration towards improvement in decision making process, response time reduction for critical academic issues, and knowledge sharing coupled with additional set of benefits [22]. In order to take advantage of cloud computing implementation combined with KM concepts, any functional model being considered for development must have a blend of best $\mathrm{KM}$ practices and appropriate infrastructure for better knowledge management and knowledge sharing [27].

\section{ANALYSIS AND DISCUSSION}

The objective of this study is to perform an in-depth systematic review of the literature of cloudbased knowledge management. Despite the fact that this is a highly interesting topic, very limited research work has been undertaken in this area. Therefore, different research papers were studied on similar topics that concluded cloud computing offers an integrated alternative solution to knowledge management implementation. Nevertheless, adoption of new technology also comes with benefits, risks and challenges. Hence, cloud computing's latest technological features offer on demand modified solutions to organization's specific needs at a reasonable cost. Some of the associated benefits from HEI's perspective are:

a. Platform compatibility poses a major challenge towards shifting to new technology from existing one that requires a robust and flexible infrastructure to meet the requirement of new tools. However, cloud adoption eliminates this challenge by offering Platform as Service (PaaS) features.

b. Rapid rate of new technology adoption with customized features is another benefit.

c. Traditional adoption of new technology is complex and poses a huge financial burden upon the organization that involves knowledge transfer, staff training, and equipment costs. Often limited and tightly controlled budget of HEI holds back such ventures. However, cloud offers a cost effective and easy to manage services for technological adoption.

d. Cloud offers very intuitive and user-friendly knowledge management creating and sharing options. Office 360 just offers those kinds of solution. Decision making becomes much easier with knowledge sharing.

e. Cloud eliminates the risk of knowledge security with knowledge integration by offering a highly secured and beneficial private cloud feature.

f. On demand storage is very flexible to meet the needs of ever-growing data for any organization with reliability and security.

g. Managed service platform feature of cloud computing is highly reliable and aligns with in-house infrastructure. The Service Level Agreement (SLA) offers a guaranteed and uninterrupted services offering all year round at all times. Organizations can benefit from redundant pool of IT services. [28]

A survey conducted by [29] to identify the expected benefits of cloud adoption and result as shown in Figure 3.

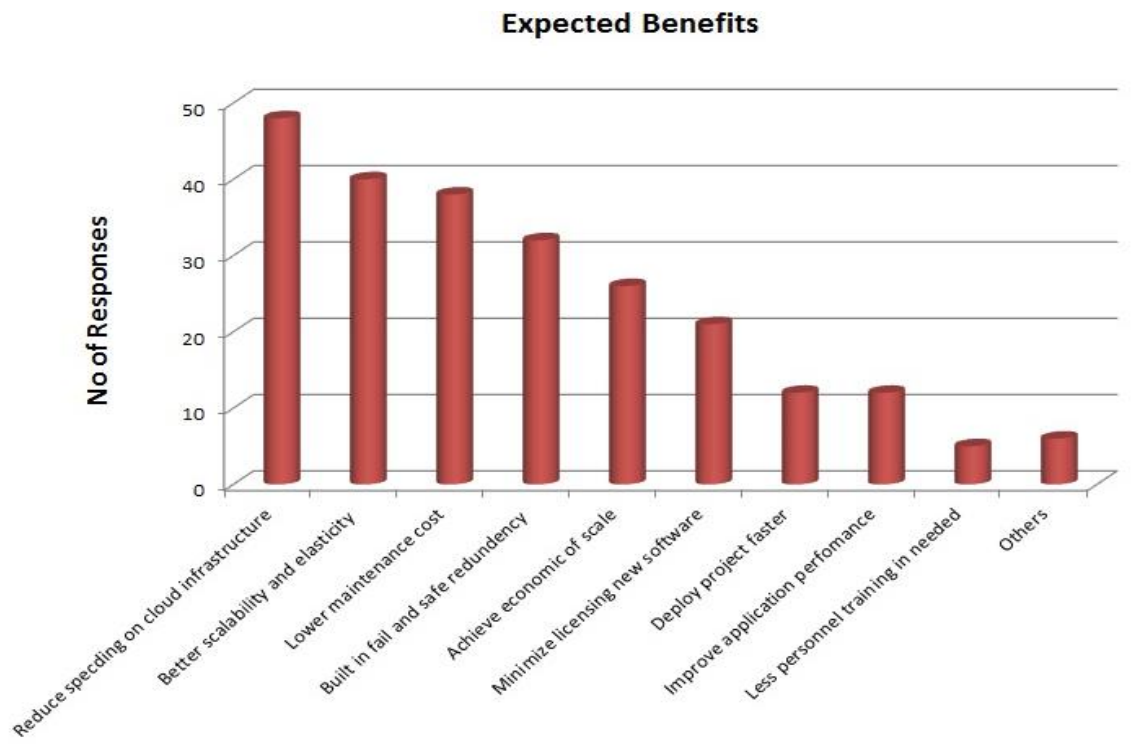

Figure 3. Primary drivers/benefits for cloud adoption [29] 
Despite advantages, there a many shortcoming and challenges posed by cloud-based knowledge management. Some of them are:

a. Data migration and integration is a major challenge while relocating data from one place to another followed by integration and switching of vendors.

b. Reliability of the data can be compromised while moving sensitive data in the companies who are new to adoption of this technology. Hence cloud computing is more recommended with highly experienced organizations.

c. Service provider dependency is another challenge posed by this technology.

d. Data privacy and security is always at risk while moving data to cloud that may be comprised with cybercrime.

e. Tradition IT infrastructure is possibly more robust maintain and handle data storage as opposed to location on cloud.

Cloud challenges describe by [30] based on research conducted by Enterprise Panel (National Institute of Standards and Technology (NIST), 2009) in Aug 2008 as shown in Figure 4. The Figure 4 result shown that security remains the main challenges even till date and rest of challenges minimized according to cloud computing maturity with the passage of time. The Figure 5 shows the benefits and challenges of Cloud Computing with $(\checkmark)$ check mark and (x) cross correspondingly.

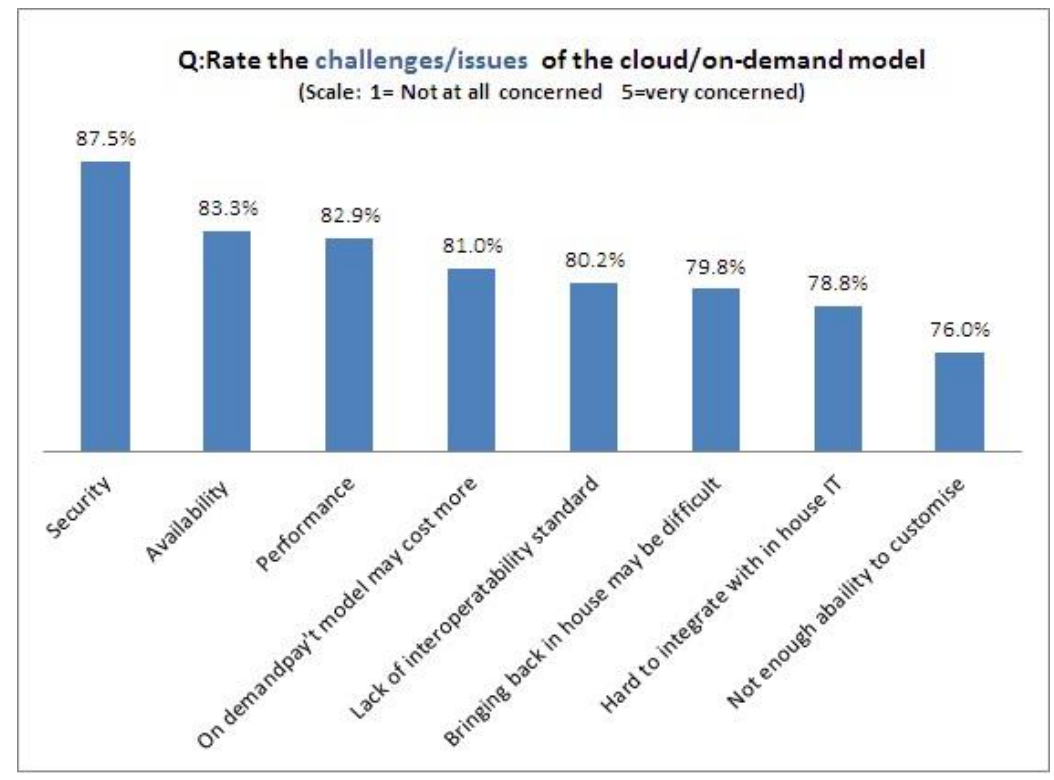

Figure 4. Cloud computing adoption challenges (NIST, 2009)

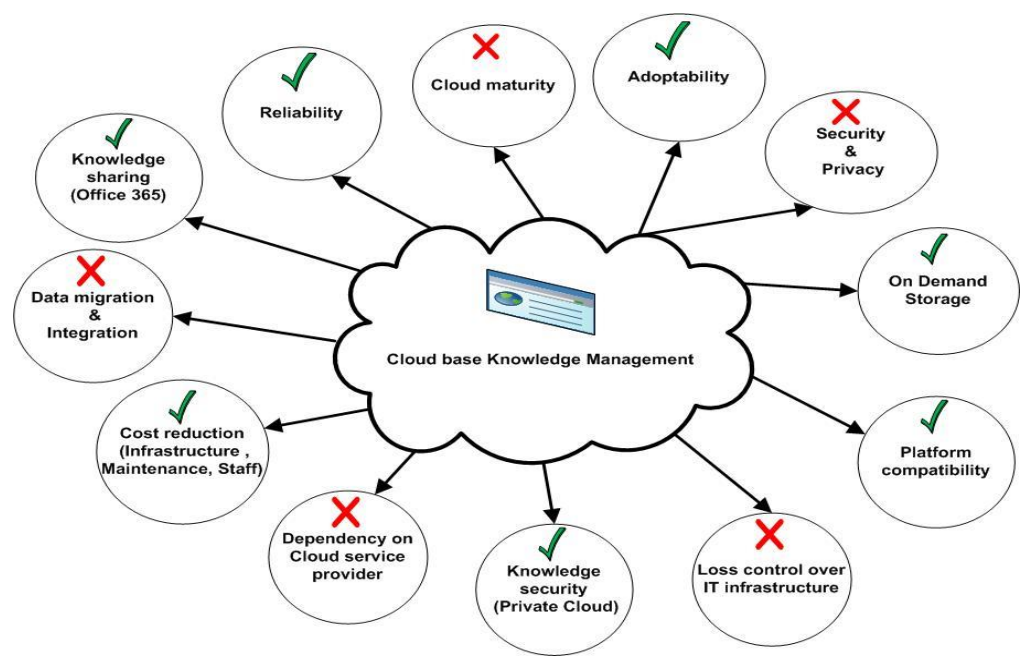

Figure 5. Benefits and Challenges of cloud based knowledge management 


\section{CONCLUSION}

This study concludes with the discussion of integration of knowledge management and cloud computing benefits with Higher Education Institutions. The results indicate that cloud-based knowledge management offer cost effective technological and methodical solutions. The cloud based knowledge management will elevate the institution's success with an upward shift in the educational methodology. Consequently, this will yield provision of best knowledge sharing practices between intra and inter institutions. Additionally, it will further assist decision making processes more accurate and efficient with robust data reliability. Lastly, teaching load management and teacher-student communication will be enhanced. Eventually, the community would be benefited with knowledge serving. The benefits and challenges go hand in hand with the adoption of new technology switching from existing system to the new one. However, literature review indicates that benefits are far more promising; count more in number that tend to shadow the challenges. Nonetheless challenges still needs to be addressed and cannot be totally ignored.

Moreover, the above identified challenges must be considered to manage and addressed according to the needs of an organization. According to the Cloud Industry Forum's report, 99\% of cloud-based KMS users have barely experienced any security breach even though data security is a major notable concern. Lastly, cloud computing will allow organizations to better perform with effective digital solutions and have a competitive advantage of any organizations.

\section{ACKNOWLEDGEMENTS}

This research is funded by Fundamental Research Grant Scheme (FRGS) with the Ref: FRGS/1/2018/ICT04/UMT/02/2. FRGS is a research grant from the Ministry of Education (MOE) Malaysia

\section{REFERENCES}

[1] C. Wang, et al., "A framework for management of massive knowledge in cloud environment," Biomedical Engineering and Informatics (BMEI), 2014 7th International Conference on, 2014.

[2] N. K. Agarwal and L. N. Marouf, "Initiating knowledge management in colleges and universities: A template," International Journal of Knowledge Content Development \& Technology, vol. 4, pp. 67-95, 2014.

[3] A. Schmitz, et al., "Universities as Knowledge Intensive Business Services - A Systematic Literature Review and a Case Study of a Research Group," International Journal of Engineering and Innovative Technology (IJEIT), vol. 3, 2014.

[4] C. A. Adams, "Sustainability reporting and performance management in universities: Challenges and benefits," Sustainability Accounting, Management and Policy Journal, vol. 4, pp. 384-392, 2013.

[5] A. Al-Rasheed, et al., "Toward a Cloud Based Knowledge Management System of E-learning Best Practices," New Perspectives in Information Systems and Technologies, Springer, vol. 1, pp. 115-125, 2014.

[6] C. Stergiou and K. E. Psannis, "Efficient and secure BIG data delivery in Cloud Computing," Multimedia Tools and Applications, vol. 76, pp. 22803-22822, 2017.

[7] M. Rafiq, et al., "Innovative trends in knowledge management: A cloud computing perspective," Proceedings of the First Middle East Conference on Global Business, Economics, Finance and Banking (ME14 DUBAI Conference), 2016.

[8] R. Alexander, "Implicit, Tacit, or Explicit: All Knowledge Is Valuable. Available: https://bloomfire.com/blog/implicit-tacit-explicit-knowledge/.

[9] V. S. Anantatmula, "Designing Meaningful KM Processes to Improve Organizational Learning," Trends in Information Management, vol 5, 2009.

[10] L. Whyte, "Development of a Knowledge management strategy for academic staff," 2008.

[11] M. A. Ismail and L. Chua, "Implication of knowledge management (KM) in higher learning institution," International Conference on Knowledge Management, PWTC, Kuala Lumpur, 2005.

[12] M. Laal, "Knowledge management in higher education," Procedia Computer Science, vol. 3, pp. 544-549, 2011.

[13] M. Al-Qurishi, et al., "A framework of knowledge management as a service over cloud computing platform," Proceedings of the International Conference on Intelligent Information Processing, Security and Advanced Communication, 2015.

[14] I. Arpaci, "Understanding and predicting students' intention to use mobile cloud storage services," Computers in Human Behavior,vol. 58, pp. 150-157, 2016.

[15] K. S. Slabeva, et al., "Grid and cloud computing: a business perspective on technology and applications," Heidelberg [Germany], New York, Springer, 2010.

[16] "Cloud Computing - Types of Cloud," 2018. Available: https://www.esds.co.in/blog/cloud-computing-typescloud/\#sthash.4Jhcx7fb.dpbs.

[17] “Cloud computing." Available from: https://en.wikipedia.org/wiki/Cloud_computing.

[18] I. Arpaci, "Antecedents and consequences of cloud computing adoption in education to achieve knowledge management," Computers in Human Behavior, vol. 70, pp. 382-390, 2017. 
[19] M. A. Mostefai, et al., "Implementing knowledge management systems in cloud-based environments: A case study in a computer science high school," Cloud Technologies and Applications (CloudTech), 2015 International Conference on, 2015.

[20] A. Al-Rasheed, et al., "Toward a Cloud Based Knowledge Management System of E-learning Best Practices," 2014.

[21] K. Iskandar, et al., "Current Issue on Knowledge Management System for future research: a Systematic Literature Review," Procedia Computer Science, vol. 116, pp. 68-80, 2017.

[22] A. Rot and M. Sobinska, "Knowledge Management in The Cloud Computing Model-Challenges, Opportunities and Risks," Computing, vol. 11, pp. 17-19, 2017.

[23] H. Ramayani, et al., "Improving organizational knowledge management (KM) through cloud based platform in higher education," Information Management and Technology (ICIMTech), 2017 International Conference on, 2017.

[24] D. J. Jiménez, et al., "Knowledge management practices for innovation: a multinational corporation's perspective," Journal of Knowledge Management, vol. 18, pp. 905-918, 2014.

[25] "Knowledge Management Systems," 2018. Available http://www.knowledge-management-tools.net/knowledgemanagement.php

[26] S. Bhatia, "Cloud-Based Knowledge Management Systems: Benefits and Risks," 2016. Available: http://www.smbceo.com/2016/06/27/cloud-based-knowledge-management-systems-benefits-and-risks/.

[27] S. Bimol, et al., "Achieving knowledge management through Cloud Computing: A case in higher education," 2014 International Conference on Computing for Sustainable Global Development (INDIACom), 2014.

[28] "Advantages and Disadvantages of Cloud Computing," 2019. Available: https://www.levelcloud.net/whylevelcloud/cloud-education-center/advantages-and-disadvantages-of-cloud-computing/.

[29] T. Kajiyama, et al., "To cloud or not to cloud: how risks and threats are affecting cloud adoption decisions," Information \& Computer Security, vol. 25, pp. 634-659, 2017.

[30] Noor A.S.M., Deris M.M., "Failure recovery mechanism in neighbor replica distribution architecture," Lecture Notes in Computer Science.Vol. 6377 LNCS, Issue M4D, 2010, Pages 41-48. Springer Nature. 2010.

[31] Mohd. Noor, A.S., Mat Deris, M. "Extended heartbeat mechanism for fault detection service methodology" Communications in Computer and Information Science Vol. 63, pp. 88-95. Springer Nature. 2009

\section{BIOGRAPHIES OF AUTHORS}

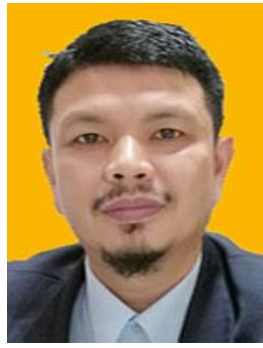

Dr. Ahmad Shukri Mohd Noor is an Associate Professor of Computer Science and Deputy Dean at School of Informatics Applied Mathematics, Universiti Malaysia Terengganu (UMT), Malaysia. He has published more than 50 research papers in various referred journals, conferences, seminars and symposiums. He is also appointed as Editor for various Scopus indexed journals (special issue) and conferences. He reviews various papers in refereed journals such as IEEE and Elsevier. He was appointed as General Chair and technical committee for various conferences. He received several invitations as invited speaker for various conferences. He is also a Google Online Professional Certified as well as Cloud Professional Certified.

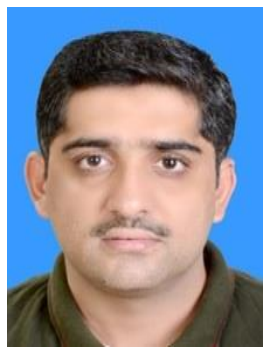

Mr. Muhammad Younas is a second year PhD student Research Scholar in the School of Informatics Applied Mathematics, Universiti Malaysia Terengganu (UMT), Malaysia. Mr. Muhammad Younas obtained his Master and Bachelor degrees in Computer Science from GC University and Bahuddin Zakaria University, Pakistan respectively. His current research focused in the field of cloud based knowledge management and its frameworks within higher education institutions. He worked as a software engineer in one of the famous organization of Pakistan.

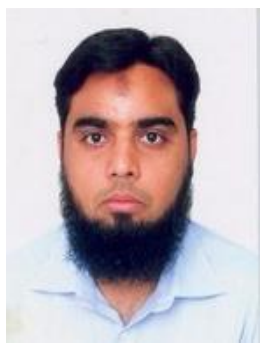

Dr. Muhammad Arshad working as an Assistant Professor in Deanship of E-Learning and Information Technology of Jazan University, Kingdom of Saudi Arabia. He has successfully completed PhD in Electrical and Electronic Engineering from Universiti Teknologi PETRONAS, Malaysia and MSc in Mobile and High Speed Telecommunication Networks with distinction from Oxford Brookes University, United Kingdom.. He has published research papers in various referred journals, conferences, seminars and symposiums. He is Graduate member of British Computer Society, Professional member of Inteernational Association of Engineers and lifetime membership of Pakistan Engineering Council. 